\title{
cDNA-AFLP transcriptional profiling reveals genes expressed during flower development in Oncidium Milliongolds
}

\author{
X. Qian*, M.J. Gong*, C.X. Wang and M. Tian \\ Research Institution of Subtropical Forestry, Chinese Academy of Forestry, \\ Fuyang, Zhejiang Province, China \\ *These authors contributed equally to this study. \\ Corresponding author: M. Tian \\ E-mail: tmin115@163.com
}

Genet. Mol. Res. 13 (3): 6303-6315 (2014)

Received April 8, 2013

Accepted September 13, 2013

Published February 21, 2014

DOI http://dx.doi.org/10.4238/2014.February.21.5

\begin{abstract}
The flower developmental process, which is crucial to the whole lifecycle of higher plants, is influenced by both environmental and endogenous factors. The genus Oncidium is commercially important for cut flower and houseplant industry and is ideal for flower development studies. Using cDNA-amplified restriction fragment length polymorphism analysis, we profiled transcripts that are differentially expressed during flower development of Oncidium Milliongolds. A total of 15,960 transcript-derived fragments were generated, with 114 primer sets. Of these, 1248 were sequenced, producing 993 readable sequences. BLASTX/N analysis showed that 833 of the 993 transcripts showed homology to genes in the NCBI databases, exhibiting functions involved in various processes, such as signal transduction, energy conversion, metabolism, and gene expression regulation. The full-length mRNAs of SUCROSE SYNTHASE 1 (SUS1) and LEAFY (LFY) were cloned, and their expression patterns were characterized. The results showed that the expression levels of SUS1 and $L F Y$ were similar during flower development. To confirm the function of SUS1 in flower buds,
\end{abstract}


carbohydrate content and sucrose synthase activity were determined. The results showed that changes in sucrose content and sucrose synthase activity reflected SUS1 expression levels. Collectively, these results indicate that SUS1 influences flower development by regulating $L F Y$ expression levels through changing the sucrose content of flower buds.

Key words: Flower development; cDNA-AFLP; Oncidium orchid; Transcript-derived fragment; Semi-quantitative RT-PCR

\section{INTRODUCTION}

The process of flowering is essential for the entire life cycle of higher plants, and has long been the focus of scientific studies to understand the developmental, physiological and molecular mechanisms underlying its regulation (Cockram et al., 2007; Dennis and Peacock, 2007; Komiya and Shimamoto, 2008; Colasanti and Coneva, 2009). Previous studies divided the flowering process into 3 progressive stages; namely, determination of flowering, flower evocation, and floral organogenesis and development (Yong et al., 2000). The first stage lays the foundation for the subsequent stages, and is controlled by several pathways (including the floral repression pathway and the carbohydrate promotion pathway) that function independently or together, depending on the species (Levy and Dean, 1998). A number of genes that play a role in the 1st stage have been cloned (Levy and Dean, 1998). In addition, genes involved in the 2nd stage have been classified as floral meristem identity genes, and include the well-known LEAFY (LFY), APETALA1/2 (AP1/2), and UNUSUAL FLORAL ORGANS (UFO) (Levin and Meyerowitz, 1995; Liljegren et al., 1999). The molecular mechanisms of organogenesis and the development of flowering have been described by the ABCDE model (Theissen and Melzer, 2007). Within this model, $L F Y$ is a major regulator that integrates floral inductive signals at the first 2 developmental stages, and controls the floral homeotic genes at the third stage (Yu et al., 2004). Another potential regulator of flowering is carbohydrate sucrose, which has been reported to both promote and delay flowering, indicating that it also functions as a signal molecule (Smeekens, 2000). Of interest, some studies have suggested that the expression of $L F Y$ is influenced by the application of sucrose (Roldán et al., 1999; Ohto et al., 2001; Lebon et al., 2008).

Oncidium Milliongolds is a member of the genus Oncidium. It has commercial value in the form of cut flowers and houseplants (Liau et al., 2003), and it differs from other commercial orchid genera because of its dominant yellow coloration that is marked with red patterns (Hieber et al., 2006). Unique flower shapes and color combinations make members of this genus ideal for the chemical and molecular genetic analyses of flower development. An AP3-like MADS box gene, OMADS3 (Hsu and Yang, 2002), and an AGL6-like gene, OMADS1 (Hsu et al., 2003), were cloned from the flower buds of Oncidium Gower Ramsey. Using RT-polymerase chain reaction (PCR) and RACE, Hieber et al. (2006) identified and characterized 5 genes involved in the pigment synthesis of Oncidium Gower Ramsey. However, further studies on genes involving Oncidium flower development are required. In particular, there has been no transcriptome-scale analysis of gene expression during Oncidium flower development; yet, such research could potentially provide a platform for revealing the molecular mechanisms underlying the regulation of Oncidium flower development. 
AFLP markers have been proven very useful for assessing a number of polymorphic loci (Misra et al., 2010; Ghosh et al., 2011). In addition, the cDNA-AFLP technique has been shown to be a robust, high-throughput, and genome-wide analysis tool for gene discovery (Bachemn et al., 1998; Wang et al., 2009; Ji et al., 2011; Yu et al., 2012). This study aimed to apply the cDNA-AFLP technique to the developmental process of Oncidium Milliongolds flower buds, identify transcripts that are differentially expressed during flower development, and validate the expression patterns through quantitative real-time PCR (qRT-PCR). Fulllength mRNA sequences of SUCROSE SYNTHASE 1 (SUS1) and LFY were obtained through this analysis, and used to investigate the relationship between sucrose and $L F Y$ regulation.

\section{MATERIAL AND METHODS}

\section{Plant materials}

Oncidium Milliongolds plants were grown in greenhouses of Lvyuan Garden Co. Ltd. (Fuyang, China), under natural light, and at controlled temperatures ranging from $23^{\circ}$ to $27^{\circ} \mathrm{C}$. Flower buds of different sizes were divided into 6 developmental stages, based on microscopic studies (stage 1: 0-1 mm, stage 2:1-2 mm, stage 3: 2-5 mm, stage 4: 5-8 mm, stage 5: 8-10 $\mathrm{mm}$, and stage 6: flowers in bloom; Figure 1). For RNA extraction, the flower buds of all 6 stages, together with the juvenile leaves, were collected, immersed in liquid nitrogen, and stored at $-80^{\circ} \mathrm{C}$ until use.

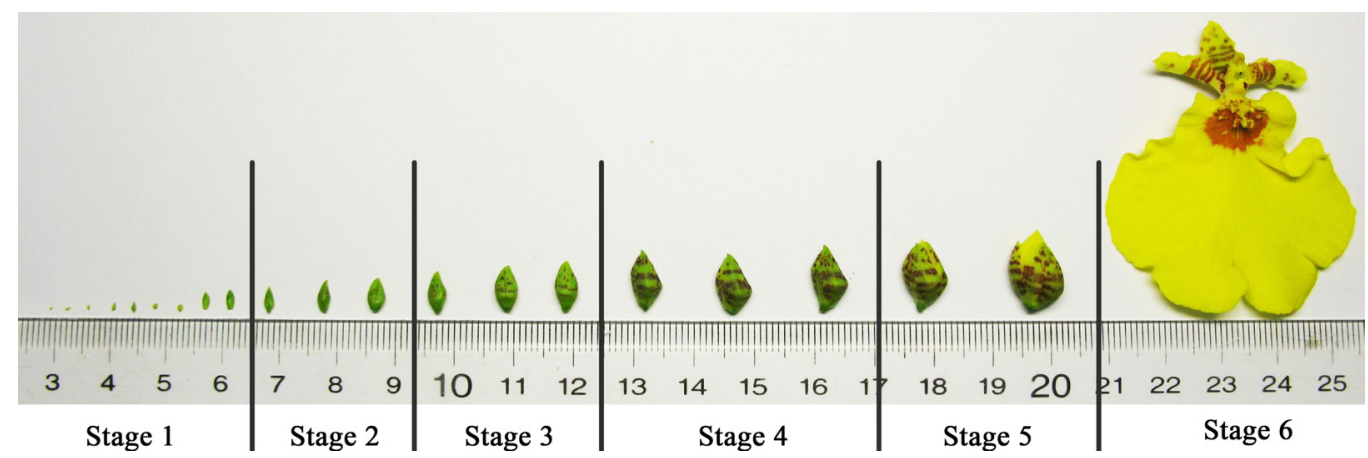

Figure 1. Developmental stages of Oncidium 'Milliongolds' flower buds. Stage 1 = 0-1 mm, stage 2 $=1-2 \mathrm{~mm}$, stage $3=2-5 \mathrm{~mm}$, stage $4=5-8 \mathrm{~mm}$, stage $5=8-10 \mathrm{~mm}$, stage $6=$ blooming flowers

\section{RNA preparation, cDNA synthesis, and cDNA-AFLP reaction}

Total RNA was isolated from $500 \mathrm{mg}$ of the frozen flower buds and leaves using the Trizol $^{\mathrm{TM}}$ extraction method (Invitrogen, Carlsbad, CA, USA) and treated with Dnase following manufacturer protocols. The quality and integrity of the RNA were tested by running $2 \mu \mathrm{L}$ total RNA on a formamide denaturing gel, along with a DNA ladder (Takara Biotechnology Co., Ltd., Dalian, China). RNA quantity was determined using a UNICO ${ }^{\mathrm{TM}} \mathrm{UV}-2100$ spectrophotometer (Unico, Shanghai, China). First- and 2nd-strand cDNA synthesis was carried out following manufacturer protocols for the PolyATtract mRNA Isolation System III kit (Pro- 
mega Corp., Madison, WI, USA) using oligo dT-containing primers. The resulting doublestranded cDNA was separated on agarose gel to confirm the size of the cDNA samples.

Approximately $1 \mu \mathrm{g}$ cDNA was digested by EcoRI and MseI (New England Biolabs Inc., Beverly, MA, USA). The digested products were ligated to adapters with T4 DNA ligase (New England Biolabs Inc.). The adapter sequences were as follows: EcoRI adapters, 5'-CTCGTAGACTGCGTACC-3' and 3'-CTGACGCATGGTTAA-5'; MseI adapters, 5'-GA CGATGAGTCCTGAG-3' and 3'-TACTCAGGACTCAT-5'.

The ligated products were pre-amplified with the following primers: EcoRI, 5'-GACTGCGTACCAATTC-3'; MseI, 5'-GATGAGTCCTGAGTAA-3'. Twenty cycles of preamplification was performed under the following conditions: $30 \mathrm{~s}$ at $95^{\circ} \mathrm{C}, 1 \mathrm{~min}$ at $56^{\circ} \mathrm{C}$, and $1 \mathrm{~min}$ at $72^{\circ} \mathrm{C}$. All PCR amplifications were performed in a $\mathrm{C} 1000^{\mathrm{TM}}$ Thermal Cycler (Bio-Rad Laboratories, Hercules, CA, USA), and the Taq enzyme and buffers were obtained from Takara Bio Inc., unless otherwise specified. The amplified products were analyzed on $1.2 \%$ agarose gel, and primarily ranged between 100 and $1000 \mathrm{bp}$. The final templates were then diluted 15fold with sterile water, and equal amounts of the template were amplified using primers with selective nucleotides at the 3'-end (EcoRI: GTC, GCT, ATG, TGA, GTA, GAT, ATC, ACT, TAC, TCA, and CAT; MseI: TCG, TGC, CTG, CGT, GTC, GCT, ACG, AGC, CAG, CGA, GCA, AGT, TAG, TGA, GTA, GAT, ACT, TAC, TCA, CAT, CTA, ATC, GAC, and ATG). One hundred and fourteen combinations of an Eco primer and an Mse primer were chosen for selective amplification (data not shown). The conditions for the selective PCR were: initial incubation at $95^{\circ} \mathrm{C}$ for $4 \mathrm{~min} ; 13$ cycles of $30 \mathrm{~s}$ at $95^{\circ} \mathrm{C}, 1 \mathrm{~min}$ at $65^{\circ} \mathrm{C}$, and $1 \mathrm{~min}$ at $72^{\circ} \mathrm{C}$, with the annealing temperature reduced by $0.7^{\circ} \mathrm{C}$ per cycle; and a final round of 24 cycles of $30 \mathrm{~s}$ at $95^{\circ} \mathrm{C}, 1 \mathrm{~min}$ at $56^{\circ} \mathrm{C}$, and $1 \mathrm{~min}$ at $72^{\circ} \mathrm{C}$. Amplified samples were heated at $95^{\circ} \mathrm{C}$ for $5 \mathrm{~min}$ after the addition of a one-fifth volume dye solution. The heat-denatured products were loaded on $6 \%$ denaturing polyacrylamide sequencing gels, and run for $2 \mathrm{~h}$ at a constant power of $85 \mathrm{~W}$ in $1 \mathrm{X}$ TBE electrophoresis buffer. Finally, the gels were silver stained and developed.

\section{Isolation and re-amplification of transcript-derived fragments (TDFs)}

Polymorphic TDFs were found based on the presence, absence, or differential intensity of the gel bands. The bands representing the TDFs were excised from the gels with maximum care to avoid any contaminating fragments, eluted in $30 \mu \mathrm{L}$ sterile double-distilled water for $10 \mathrm{~min}$ at $95^{\circ} \mathrm{C}$, and then centrifuged at $12,000 \mathrm{~g}$ for $5 \mathrm{~min}$ at $4^{\circ} \mathrm{C}$. Next, $3 \mu \mathrm{L}$ of the aliquot was used for re-amplification in a total volume of $50 \mu \mathrm{L}$, using the same set of corresponding selective primers. The PCR program was: 30 cycles of $30 \mathrm{~s}$ at $95^{\circ} \mathrm{C}, 1 \mathrm{~min}$ at $56^{\circ} \mathrm{C}$, and $1 \mathrm{~min}$ at $72^{\circ} \mathrm{C}$. The PCR products were verified on $2 \%$ agarose gel, and each single band was isolated and eluted using the AxyPrep ${ }^{\mathrm{TM}}$ DNA Gel Extraction kit (Axygen, Inc., Union City, CA, USA).

\section{Subcloning and sequencing of TDFs}

The eluted TDFs were cloned into the plasmid pGEM-Teasy ${ }^{\circledR}$ vector (Promega Corp.) following manufacturer protocols. Plasmids were then transformed into E. coli DH5 $\alpha$ competent cells (Takara Biotechnology Co., Ltd.). Next, the transformants were plated at low density on Luria-Bertani medium plates containing $150 \mathrm{mg} / \mathrm{L}$ ampicillin, $25 \mathrm{mg} / \mathrm{L} \mathrm{X}-\mathrm{Gal}$, and $25 \mathrm{mg} / \mathrm{L}$ 
IPTG, and cultured at $37^{\circ} \mathrm{C}$ for 12 to $14 \mathrm{~h}$. One to 3 white colonies were selected randomly for the sequencing analysis of each cloned TDF. TDF sequencing was carried out by Sangon Biotech Co. Ltd. (Shanghai, China). The TDF sequences were analyzed for homology with gene sequences using publicly available non-redundant genes, ESTs, and transcripts in the NCBI (http://www.ncbi.nlm.nih.gov/) database using the BLASTn and BLASTX algorithms.

\section{RT-PCR}

To clone the full-length mRNA of $L F Y$ and SUS1 from Oncidium Milliongolds, total RNA was extracted from the flower buds of all 6 developmental stages and leaves, as previously described. First-strand cDNAs were synthesized with RevertAid ${ }^{\mathrm{TM}}$ First-Strand cDNA Synthesis Kit (Fermentas, Hanover, MD, USA) following the manufacturer protocols. Primers were designed based on the sequences of Oncidium Gower Ramsey LFY mRNA (GenBank ID: FJ618567.1) and Oncidium Goldiana SUS1 mRNA (GenBank ID: AF530567). The primer sequences were: $L F Y$, 5'-ATGCGGGAGGAGGAGGTGGACGAT-3' and 5'-TCGGAGCCCAGACTCAGACC-3'; SUS1， 5'-CTCATAACTCCGTTCACTCC-3' and 5'-TCACATCAATAAACCCAAAA-3'. The same PCR program was used as that for the reamplification. The PCR products were checked on 1.2\% agarose gels, cloned into the plasmid vector pGEM-Teasy ${ }^{\circledR}$, transformed into Escherichia coli DH5 $\alpha$ competent cells, and sequenced.

\section{qRT-PCR and data analysis}

For the semi-quantitative RT-PCR, primers for $L F Y$ and $S U S 1$ were designed based on the sequencing results of the full-length mRNA. The primer sequences were: $L F Y$, 5'-TGCCCTACTAAGGTGACAAACC-3' and 5'-CTTCGTGGGAACGTACCAGAT-3'; SUS1, 5'-TTCTGAATCGGCATCTTTCGTC-3' and 5'-CCAACCTTTCTCCAAGCCAAG-3'. Two micrograms of total RNA from both flower buds and the leaves from each developmental stage were subjected to first-strand cDNA synthesis following manufacturer protocols (Fermentas, Thermo Fisher Scientific, Shanghai, China). The house-keeping gene $\beta$-actin (GenBank ID: HQ316804) (primer sequences: 5'-CTCGCCTCCTTCCTACCTAACA-3' and 5'-CATCTCCTCGCCATTACTCACC-3') was used as an internal standard in the real-time PCR, which was performed on a 7300 Real-Time PCR System (Applied Biosystems, Forest City, CA, USA) following the SYBR ${ }^{\circledR}$ Premix Ex Taq ${ }^{\mathrm{TM}}$ (Perfect Real Time) Kit (Takara) manufacturer protocol. Dissociation curves were generated for each reaction to ensure specific amplification. Threshold values (Ct) generated from the ABI PRISM 7300 Software Tool (Applied Biosystems) were employed to quantify relative gene expression using a comparative $2^{-\Delta \Delta \mathrm{Ct}}$ method (Livak and Schmittgen, 2001).

\section{Carbohydrate determination, enzyme activity assays, and data correlation analysis}

Flower buds of all 6 developmental stages, along with the leaves and pseudobulbs from plants undergoing vegetative and reproductive growth, were collected, immediately frozen in liquid nitrogen, and stored at $-80^{\circ} \mathrm{C}$. Sucrose, fructose, and total soluble carbohydrate contents were measured. Sucrose synthase (SS) isolation and activity assays were conducted following the methods of Yu (1985) and Lowell et al. (1989), with some modifications. Five 
millimoles/liter of $\mathrm{KCN}$ was substituted with $15 \mathrm{mM} \mathrm{MgCl}_{2}$ combined with $1 \mathrm{mM}$ ethylenediaminetetraacetic acid (EDTA), while $5 \mathrm{mM} \mathrm{NaF}$ was substituted with $2.5 \mathrm{mM}$ DTT. SS activities for the synthetic and cleavage reactions were measured in terms of sucrose production and sucrose consumption in $1 \mathrm{~g}$ fresh weight material per hour $\left(\mu \mathrm{mol}\right.$ sucrose $\left.\cdot \mathrm{g} \mathrm{FW}^{-1} \cdot \mathrm{h}^{-1}\right)$.

The correlations between SUS1 expression, $L F Y$ expression, SS activity, and sucrose content at all 6 stages of flower bud development were analyzed using the SPSS software program (IBM, USA).

\section{RESULTS}

\section{cDNA-AFLP fingerprinting}

Samples of mRNA from the flower buds and leaflets of Oncidium Milliongolds were analyzed by cDNA-AFLP fingerprinting. Approximately 18 to 25 discrete bands sized from 100 to $1000 \mathrm{bp}$ were obtained from each primer combination, and were reproducibly generated. Approximately 15,960 TDFs were generated, with 114 different primer pairs. A total of 1485 TDFs were recovered from the denaturing polyacrylamide gels (Figure 2A-F). Of these, 1248 were successfully re-amplified. The re-amplification products were subcloned and sequenced.

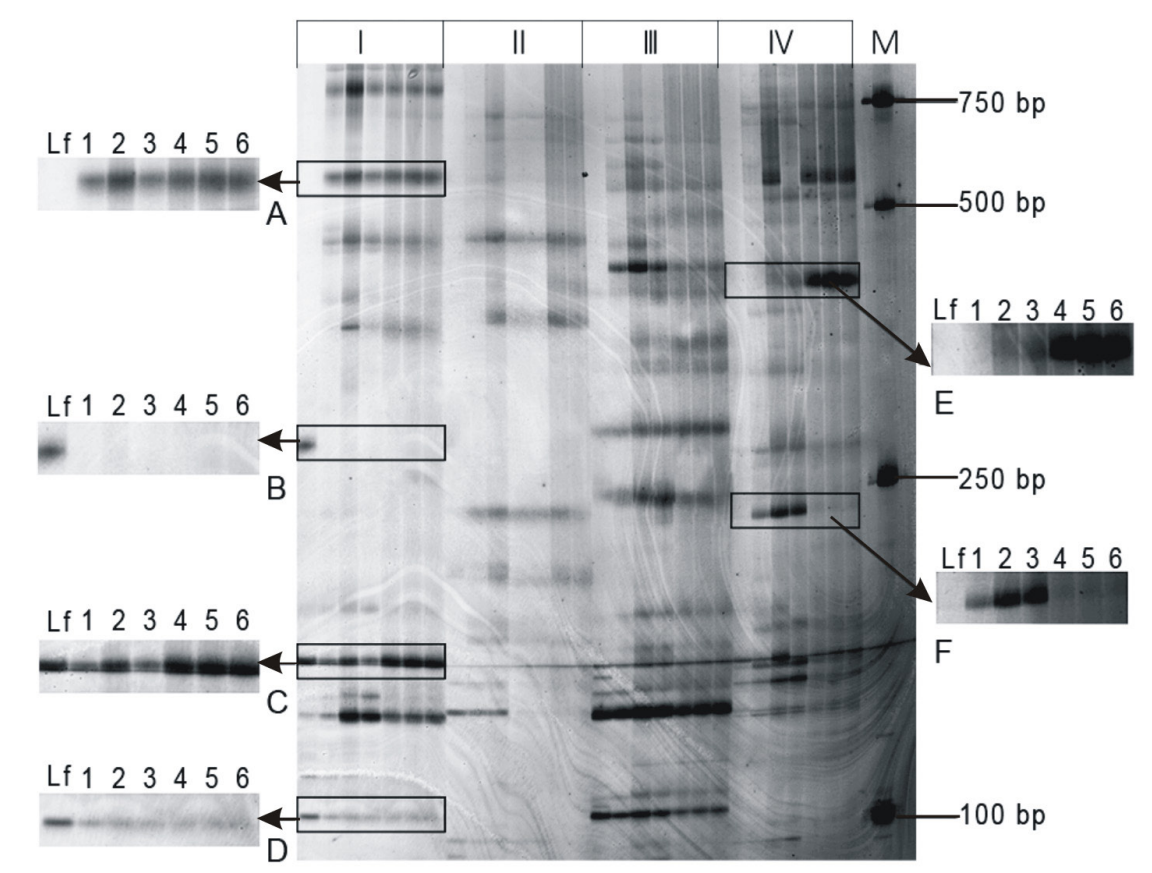

Figure 2. Representative photograph of the cDNA-AFLP fingerprinting showing different expression patterns for the transcript-derived fragments (TDFs), with close-up views showing TDFs expressed in flower buds only (A), in leaves only (B), in both leaves and flower buds $(\mathbf{C})$, at a higher level in leaves than in flower buds (D), and primarily in the late stages $(\mathbf{E})$ and early stages $(\mathbf{F})$ of flower development. $\mathrm{Lf}=$ leaves. Lanes $1-6=$ flower buds of stages 1-6; lanes $I-I V=$ fragments generated by the primer pair E-TAC + M-CGT/GTC/GCT/AGC; lane $M=$ DNA marker. 


\section{Sequence analysis of the TDFs}

Of the 1248 TDFs sequenced, 993 fragments produced readable sequences. Sequence alignment of these 993 TDFs revealed that 833 showed homology to genes with known functions, whereas 96 did not show homology to other sequences, and 64 displayed identity with unknown proteins. However, 219 of the TDFs belonged to cDNA-AFLP markers, 55 were microsatellite DNA, and 142 were non-plant sequences. All of the sequences were classified into functional groups based on their homology with known genes or proteins according to the method of Baisakh et al. (2006), with minor modifications (Figure 3). Among the TDFs with putative known functions, the majority were involved in signal transduction, metabolism, regulation of gene expression, transportation, and energy conversion. A selection of the TDFs is presented in Table 1.

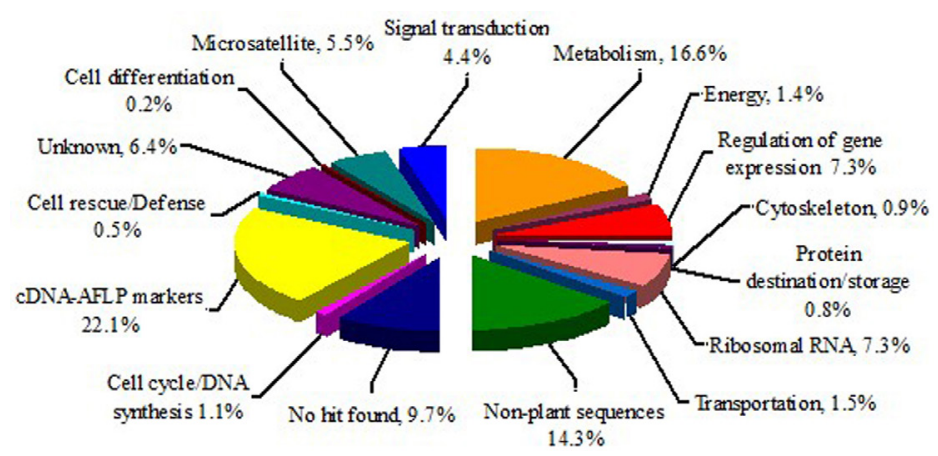

Figure 3. Functional classification of the transcript-derived fragments based on their homology.

Table 1. Selected list of the sequenced transcript-derived fragments (TDFs) with known gene sequences or proteins in the NCBI databases using the BLASTN and BLASTX algorithms.

\begin{tabular}{|c|c|c|c|c|c|}
\hline TDF No. & GenBank ID & Length (bp) & Gene homology (GenBank ID) & Organism & E-value \\
\hline TDF0073a & JG014359 & 121 & AFLP fragment linked to seedless trait (EU442614.1) & Citrus reticulata & $1 \mathrm{e}-14$ \\
\hline TDF0084a & JG014360 & 187 & GTP cyclohydrolase II (NP_201235) & Arabidopsis thaliana & $2 \mathrm{e}-14$ \\
\hline TDF0140a & JG01436 & 186 & Alpha-mannosidase (ADU20406) & Capsicum annuum & $4 \mathrm{e}-11$ \\
\hline TDF0171a & JG014370 & 224 & Lysosomal alpha-mannosidase, putative (XP 002512839) & Ricinus communis & $6 e-24$ \\
\hline TDF0173a & JG014371 & 222 & Hypothetical protein (XP002273425.1) & Vitis vinifera & $3 e-13$ \\
\hline TDF0233a & JG014382 & 312 & Cysteine synthase (ABO15564) & Glycine $\max$ & $5 e-28$ \\
\hline TDF0254a & JG014387 & 300 & Lectin-like receptor kinase (NP_001147947.1) & Zea mays & $1 \mathrm{e}-26$ \\
\hline TDF0369a & JG014431 & 247 & Heat shock protein $70(\mathrm{ACO} 71 \overline{2} 87.1)$ & Triticum aestivum & $2 \mathrm{e}-28$ \\
\hline TDF0382a & JG014437 & 174 & Transcription factor (ADG58078.1) & Lycoris longituba & $4 \mathrm{e}-13$ \\
\hline TDF0392a & JG014441 & 343 & Mobilization protein MobS (P20086.1) & Acidithiobacillus ferrooxidans & $3 e-13$ \\
\hline TDF0411a & JG014450 & 168 & Copper/zinc superoxide dismutase (ABI34607.1) & Musa formosana & $4 \mathrm{e}-14$ \\
\hline TDF0542a & JG014468 & 277 & Beta-tubulin (ACI03399.1) & Prunus salicina var. cordata & $3 e-38$ \\
\hline TDF0615a & JG014492 & 256 & $\begin{array}{l}\text { Chloroplast alpha-glucan water dikinase, putative } \\
\text { (XP_002518612.1) }\end{array}$ & Ricinus communis & $1 \mathrm{e}-20$ \\
\hline TDF06302a & JG014495 & 170 & Ion channel DMI1-like, putative (ABF99841.1) & Oryza sativa (Japonica group) & $8 \mathrm{e}-10$ \\
\hline TDF0698a & JG014512 & 326 & Helicase, putative (XP_002527838.1) & Ricinus communis & $2 \mathrm{e}-09$ \\
\hline TDF0785a & JG014523 & 343 & Sucrose synthase $1(S \bar{U} S 1)$ mRNA (AF530567.1) & Oncidium cv. 'Goldiana' & 1e-133 \\
\hline TDF07892a & JG014526 & 234 & Elongation factor 1 alpha (ACT36602.1) & Quercus macrocarpa & $8 \mathrm{e}-21$ \\
\hline TDF0866a & JG014541 & 227 & Fructose-bisphosphate aldolase mRNA (EU975551.1) & Zea mays & $2 \mathrm{e}-24$ \\
\hline TDF0868a & JG014542 & 274 & Anthocyanidin synthase (BAJ07044.1) & Cyclamen graecum & $2 \mathrm{e}-05$ \\
\hline TDF1122a & JG014605 & 199 & Homo sapiens $12 \mathrm{BAC}$ RP13-501J24 (AC122687.2) & Homo sapiens & $1 e-70$ \\
\hline TDF1137a & JG014611 & 266 & Endomembrane protein 70 (ADQ43185.1) & Thellungiella parvula & $2 \mathrm{e}-06$ \\
\hline TDF1153a & JG014613 & 379 & Proline-rich protein APG isolog (AAB63641.1) & Arabidopsis thaliana & $1 e-34$ \\
\hline TDF1205a & JG014621 & 273 & Cyclin, putative (XP_002527530.1) & Ricinus communis & $5 e-15$ \\
\hline TDF1242a & JG014633 & 180 & $\begin{array}{l}\text { Phytochrome and flowering time protein } 1 \\
(P F T 1) \text { (ABM81545.1) }\end{array}$ & Triticum aestivum & $3 e-13$ \\
\hline
\end{tabular}




\section{Cloning of the full-length SUS1 and LFY mRNAs}

Several studies have suggested that sucrose acts as signal during the transition to flowering. Hence, the Oncidium Milliongolds SUS1 mRNA was cloned and sequenced, because SS both cleaves and synthesizes sucrose and, thereby, controls its flux. The sequence was submitted to the GenBank database (GenBank ID: JF416946). Sequence analysis indicated that SUS1 mRNA contained 2659 nucleotides with an open reading frame of $2448 \mathrm{bp}$. The sequence was predicted to encode a protein of 815 amino acids. Comparative analysis revealed that the SUS1 mRNA of Oncidium Milliongolds displayed high similarity to those of Oncidium Goldiana (GenBank ID: AF530567.1) (99\%), Dendrobium officinale (GenBank ID: HQ856835.1) (82\%), x Mokara Yellow (GenBank ID: AF530568.1) (82\%), and Zea mays (GenBank ID: NM_001111941.1) (79\%).

In addition, because several studies have found that sucrose promotes or delays floral transition by affecting $L F Y$ expression (Ohto et al., 2001), we cloned and sequenced the LFY mRNA of Oncidium Milliongolds (GenBank ID: HM358866) to examine its expression relative to SUS1 expression. Sequence analysis revealed that the $L F Y$ mRNA was 1125 bp in length, encoded a hypothetical protein of 374 amino acids, and showed high identity with the LFY mRNA of Oncidium Gower Ramsy (GenBank ID: FJ618567.1) (98\%) and a Phalaenopsis hybrid cultivar (GenBank ID: AY969008.1) (89\%).

\section{qRT-PR analysis of $S U S 1$ and $L F Y 1$ expression patterns}

Semi-quantitative RT-PCR analysis for the flower buds at the 6 different stages and the leaves showed that the expression level of SUS1 peaked at stage 1, and then decreased during the following stages until stage 5. At this stage, a relatively high expression level was visualized. The lowest level of expression was observed at stage 6 (Figure 4A). The expression of $L F Y$ (Figure 4B) shared a very similar profile to that of SUS1. Maximum expression occurred at stage 1 , and decreased continuously during the subsequent stages, with the exception of stage 5. Only the expression level of SUS1 at stage 1 of the flower buds was higher compared to that in the leaves, whereas LFY1 expression was stronger in the flower buds of all stages compared to the leaves. However, the results of the correlation analysis showed that there was a positive correlation between the expression of SUS1 and $L F Y$ for all 6 flower bud stages (correlation coefficient, 0.943) (Table 2).

\section{Carbohydrate determination, enzyme assays, and data correlation analysis}

The results of carbohydrate determination showed that both fructose and total soluble carbohydrate contents were higher in the flower buds of all 6 stages compared to the leaves (Figure 5A), and showed similar changes over the course of flower development. Both fructose and soluble carbohydrate increased from stage 1 to stage 4 , slightly decreased at stage 5 , and peaked at stage 6 . However, the sucrose content profile was different. The sucrose content in the flower buds was higher compared to the leaves during the first 3 stages, but was lower at stages 4 and 6 , while flower buds of stage 5 contained nearly the same amount of sucrose as the leaves. The differences between sucrose and the other carbohydrates indicate that sucrose plays a different role during flower bud development. Of note, changes in sucrose content 
were positively correlated with changes in SUS1 and $L F Y$ expression levels (correlation coefficients, 0.943 and 1.000, respectively) (Table 2).

A

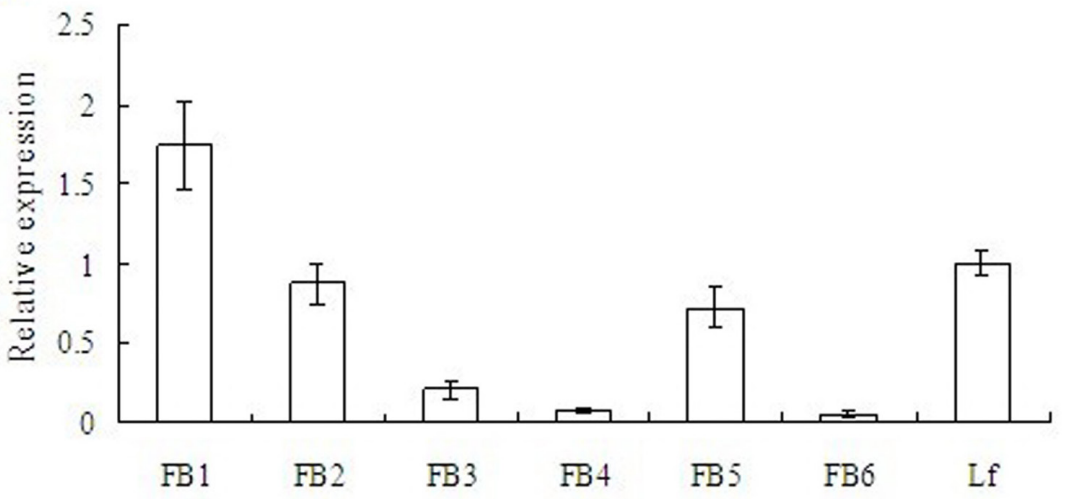

B

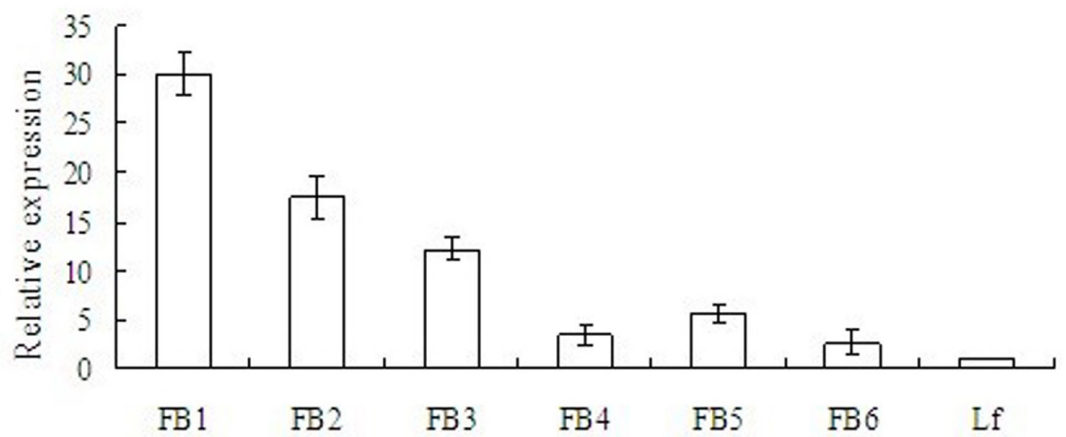

Figure 4. Semi-quantitative RT-PCR analysis of the expression patterns of $S U S 1$ (A) and $L F Y(\mathbf{B})$ in leaves and flower buds of different development stages in Oncidium 'Milliongolds'. Lf = leaves; FB1-FB6 = flower buds of stages 1-6.

Table 2. Results of correlation analysis.

\begin{tabular}{lccccc}
\hline & $L F Y$ expression & SUS1 expression & SS activity & Sucrose content & Total carbohydrate content \\
\hline FFY expression & 1.000 & & & & \\
SUS1 expression & $0.943^{* *}$ & 1.000 & & & \\
SS activity & $0.943^{* *}$ & $0.829^{* *}$ & 1.000 & & \\
Sucrose content & $1.000^{* *}$ & $0.943^{* *}$ & $0.943^{* *}$ & 1.000 & 1.000 \\
Total carbohydrate content & $-1.000^{* *}$ & $-0.943^{* *}$ & $-0.943^{* *}$ & $-1.000^{* *}$ & 0.657 \\
Fructose content & -0.657 & $-0.829^{*}$ & -0.429 & -0.657 & 1.000 \\
\hline
\end{tabular}

$\mathrm{SS}=$ sucrose synthase. ${ }^{*}$ Correlation is significant at the 0.05 level (two-tailed). ${ }^{*}$ Correlation is significant at the 0.01 level (two-tailed).

The results of the SS activity assays (Figure 5B) showed that in the flower buds of all 6 stages and in the leaves, enzyme activity was much higher for synthesis compared to cleavage. Cleavage activity never surpassed $2 \mu \mathrm{mol}$ sucrose $\cdot \mathrm{FW}^{-1} \cdot \mathrm{h}^{-1}$, and remained relatively 
stable throughout the development of the flower buds. In contrast, synthesis activity was much higher, exceeding $27 \mu \mathrm{mol}$ sucrose $\cdot \mathrm{g} \mathrm{FW}^{-1} \cdot \mathrm{h}^{-1}$ at the peak stage. SS activity associated with synthesis was positively associated with sucrose content in the flower buds, with a correlation coefficient of 0.943 . These results demonstrated that SS mainly functioned as a sucrose producer (rather than consumer) during flower bud development. From stages 1 to 4, SS activity was higher in the flower buds compared to the leaves, but was lower in the flower buds compared to the leaves during the last 2 stages. From stage 1 to 6 , synthesis-associated activity declined, showing a positive correlation with the changes in SUS1 and $L F Y$ expression levels (correlation coefficients, 0.829 and 0.943 , respectively).

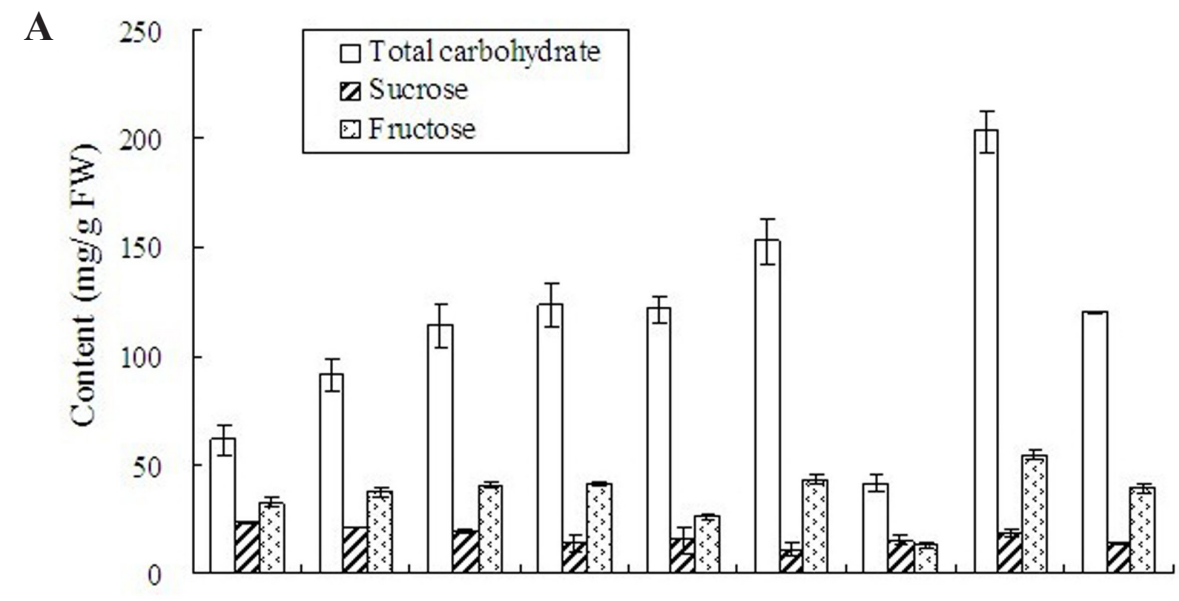

B

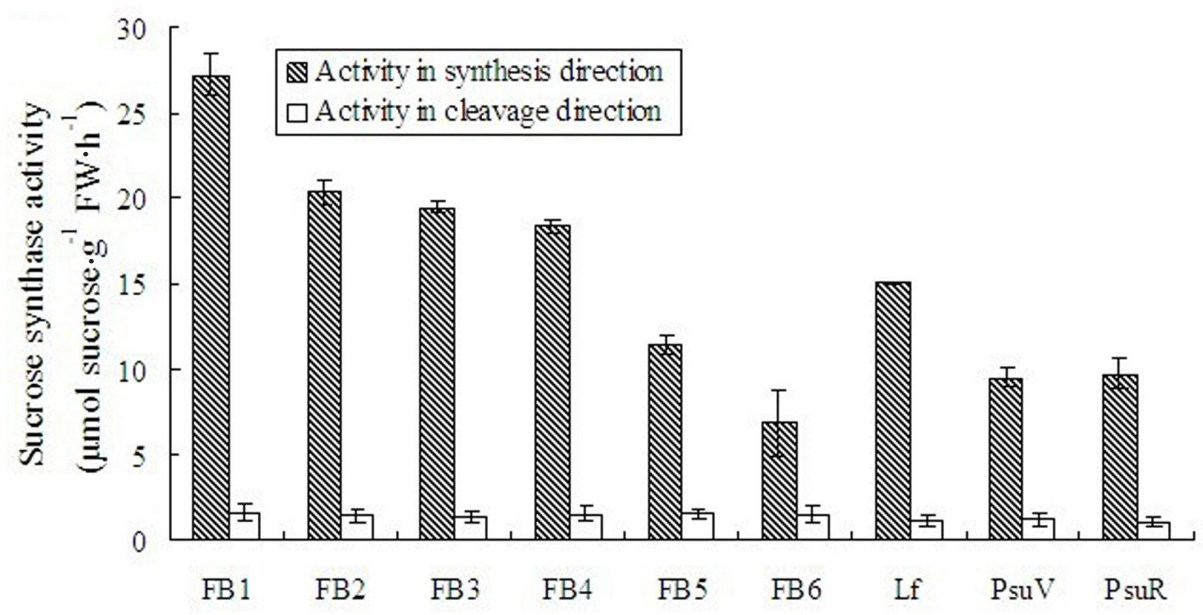

Figure 5. Determination of carbohydrate (A) and sucrose synthase activity (B) in flower buds at different development stages, leaves, and pseudobulbs in Oncidium 'Milliongolds'. FB1-FB6 = flower buds at stages 1-6; $\mathrm{Lf}=$ leaves; PsuV = pseudobulbs from plants undergoing vegetative growth; PsuR = pseudobulbs from plants undergoing reproductive growth. 


\section{DISCUSSION}

Using the cDNA-AFLP technique, we were able to detect approximately 15,960 reproducible TDFs, with 114 primer combinations. This number was within the same range found in a previous study on the flower bud development of Camellia sinensis (Ye et al., 2008). In this species, 200 TDFs were produced with 10 primer pairs from each sample. The function classification results of the TDFs generally followed the results of cDNA-AFLP analyses of other plant species, such as Spartina alterniflora Loisel (Baisakh et al., 2006) and wheat (Wang et al., 2009). Of note, a number of the TDFs did not correspond to available sequences from plants based on the homology analysis by BLASTX/N. Similar cases have been reported for Arabidopsis, in which TDFs showed significant similarity with DNA or protein sequences from animal species (De Diego et al., 2006) or microorganisms (Mondego et al., 2003). Together, these TDFs and those with no BLAST hits may be regarded as newly identified genes expressed during flower development, and warrant further investigation. However, this result should be treated with caution, because the DNA fragment lengths were too short, which might limit the search analysis. Furthermore, the present study demonstrated that cDNA-AFLP is a powerful genome-scale transcript profiling approach for identifying genes involved in Oncidium Milliongolds flower development.

In the present study, we cloned and characterized the SUS1 mRNA in Oncidium Milliongolds because sucrose was reported to act as a signal molecule that regulates a variety of genes (Koch, 1996), including genes that are involved in flowering (Ho et al., 2001; Ohto et al., 2001; Gupta and Kaur, 2005). Following a report by Roldán et al. (1999) stating that sucrose availability in the medium accelerated the flowering of late-flowering Arabidopsis ecotypes, we assessed the carbohydrate contents in our test materials. The results showed that SUS1 expression and sucrose content exhibited similar profiles in the developing flower, indicating that SUS1 might be regulating flower development by altering the content of sucrose in the flower buds. This observation raises the question of how to confirm that variation in sucrose content is regulated by changes in SUS1 expression levels. First, we assayed SS activity in both catalyzing directions. The results showed that SS acted primarily as a sucrose producer, rather than decomposer, as described by Lowell et al. (1989). Furthermore, we determined carbohydrate content and SS activity in pseudobulbs at vegetative and reproductive developmental stages. The stable expression levels of SUS1 and sucrose content in the pseudobulbs indicated that increased sucrose content in the flower buds was a result of local synthesis, rather than transport from the storage organs. Collectively, these results support that the observed increase in sucrose content in the flower buds resulted from the up-regulated expression of SUS1.

It is widely accepted that $L F Y$ is an important gene that is involved in both floral transition and flower organ morphogenesis (Blázquez et al., 1997). Ohto et al. (2001) and Blázquez et al. (1998) suggested that sucrose might delay or promote the activation of $L F Y$ in Arabidopsis, depending on its concentrations. In this study, the expression analysis revealed that $L F Y$ expression levels at different stages of flower buds mimicked that of SUS1, even though $L F Y$ was expressed at a much higher level. Overall, these results lead us to propose a putative model in which SUS1 regulates the expression of $L F Y$ through changing the sucrose content in flower buds and, thereby, ultimately affecting flower development. 


\section{ACKNOWLEDGMENTS}

Research supported by the "948” Program (\#2008-4-25), the Provincial Natural Science Foundation of Zhejiang Province (\#Y3100272), and the Program for Science and Technology from Zhejiang Province (\#2009R50034).

\section{REFERENCES}

Bachem CWB, Oomen RJFJ and Visser RGF (1998). Transcript imaging with cDNA-AFLP: a step-by-step protocol. Plant Mol. Biol. Rep. 16: 157-173.

Baisakh N, Subudhi PK and Parami NP (2006). cDNA-AFLP analysis reveals differential gene expression in response to salt stress in a halophyte Spartina alterniflora Loisel. Plant Sci. 170: 1141-1149.

Blázquez MA, Soowal LN, Lee I and Weigel D (1997). LEAFY expression and flower initiation in Arabidopsis. Development 124: 3835-3844.

Blázquez MA, Green R, Nilsson O, Sussman MR, et al. (1998). Gibberellins promote flowering of Arabidopsis by activating the $L E A F Y$ promoter. Plant Cell 10: 791-800.

Cockram J, Jones H, Leigh FJ, O'Sullivan D, et al. (2007). Control of flowering time in temperate cereals: genes, domestication, and sustainable productivity. J. Exp. Bot. 58: 1231-1244.

Colasanti J and Coneva V (2009). Mechanisms of floral induction in grasses: something borrowed, something new. Plant Physiol. 149: 56-62.

De Diego JG, David RF, Rodriguez Lorenzo JL, Grappin P, et al. (2006). cDNA-AFLP analysis of seed germination in Arabidopsis thaliana identifies transposons and new genomic sequences. J. Plant Physiol. 163: 452-462.

Dennis ES and Peacock WJ (2007). Epigenetic regulation of flowering. Curr. Opin. Plant Biol. 10: 520-527.

Ghosh S, Majumder PB and Sen MS (2011). Species-specific AFLP markers for identification of Zingiber officinale, Z. montanum and Z. zerumbet (Zingiberaceae). Genet. Mol. Res. 10: 218-229.

Gupta AK and Kaur N (2005). Sugar signalling and gene expression in relation to carbohydrate metabolism under abiotic stresses in plants. J. Biosci. 30: 761-776.

Hieber AD, Mudalige-Jayawickrama RG and Kuehnle AR (2006). Color genes in the orchid Oncidium Gower Ramsey: identification, expression, and potential genetic instability in an interspecific cross. Planta 223: 521-531.

Ho S, Chao Y, Tong W and Yu S (2001). Sugar coordinately and differentially regulates growth- and stress-related gene expression via a complex signal transduction network and multiple control mechanisms. Plant Physiol. 125: 877-890.

Hsu HF and Yang CH (2002). An orchid (Oncidium Gower Ramsey) AP3-like MADS gene regulates floral formation and initiation. Plant Cell Physiol. 43: 1198-1209.

Hsu HF, Huang CH, Chou LT and Yang CH (2003). Ectopic expression of an orchid (Oncidium Gower Ramsey) AGL6like gene promotes flowering by activating flowering time genes in Arabidopsis thaliana. Plant Cell Physiol. 44: 783-794.

Ji RQ, Song Q, Xin XF, Zhou X, et al. (2011). Isolation of fertility-related genes of multiple-allele-inherited male sterility in Brassica rapa ssp pekinensis by cDNA-AFLP. Genet. Mol. Res. 10: 4073-4083.

Koch KE (1996). Carbohydrate-modulated gene expression in plants. Annu. Rev. Plant Physiol. Plant Mol. Biol. 47: 509540.

Komiya R and Shimamoto K (2008). Genetic and epigenetic regulation of flowering in rice. Plant Biotechnol. 258: 279-284.

Lebon G, Wojnarowiez G, Holzapfel B, Fontaine F, et al. (2008). Sugars and flowering in the grapevine (Vitis vinifera L.). J. Exp. Bot. 59: 2565-2578.

Levin JZ and Meyerowitz EM (1995). UFO: an Arabidopsis gene involved in both floral meristem and floral organ development. Plant Cell 7: 529-548.

Levy YY and Dean C (1998). The transition to flowering. Plant Cell. 10: 1973-1989.

Liau CH, You SJ, Prasad V, Hsiao HH, et al. (2003). Agrobacterium tumefaciens-mediated transformation of an Oncidium orchid. Plant Cell Rep. 21: 993-998.

Liljegren SJ, Gustafson-Brown C, Pinyopich A, Ditta GS, et al. (1999). Interactions among APETALA1, LEAFY, and TERMINAL FLOWER1 specify meristem fate. Plant Cell 11: 1007-1018.

Livak KJ and Schmittgen TD (2001). Analysis of relative gene expression data using real-time quantitative PCR and the $2^{-\Delta \Delta C \mathrm{CT}}$ method. Methods 25: 402-408.

Lowell CA, Tomlinson PT and Koch KE (1989). Sucrose-metabolizing enzymes in transport tissues and adjacent sink structures in developing citrus fruit. Plant Physiol. 90: 1394-1402.

Genetics and Molecular Research 13 (3): 6303-6315 (2014)

CFUNPEC-RP www.funpecrp.com.br 
Misra A, Shasany AK, Shukla AK, Darokar MP, et al. (2010). AFLP markers for identification of Swertia species (Gentianaceae). Genet. Mol. Res. 9: 1535-1544.

Mondego JMC, Simões-Araújo JL, de Oliveira DE and Alves-Ferreira M (2003). A gene similar to bacterial translocase I (mra Y) identified by cDNA-AFLP is expressed during flower bud development of Arabidopsis thaliana. Plant Sci. 164: 323-331.

Ohto M, Onai K, Furukawa Y, Aoki E, et al. (2001). Effects of sugar on vegetative development and floral transition in Arabidopsis. Plant Physiol. 127: 252-261.

Roldán M, Gomez-Mena C, Ruiz-Garcia L, Salinas J, et al. (1999). Sucrose availability on the aerial part of the plant promotes morphogenesis and flowering of Arabidopsis in the dark. Plant J. 20: 581-590.

Smeekens S (2000). Sugar-induced signal transduction in plants. Annu. Rev. Plant Physiol. Plant Mol. Biol. 51: 49-81.

Theissen G and Melzer R (2007). Molecular mechanisms underlying origin and diversification of the angiosperm flower. Ann. Bot. 100: 603-619.

Wang X, Tang C, Zhang G, Li Y, et al. (2009). cDNA-AFLP analysis reveals differential gene expression in compatible interaction of wheat challenged with Puccinia striiformis f. sp. tritici. BMC Genomics 10: 289.

Ye AH, Yu M, Zhu L, Jiang CJ, et al. (2008). Transcriptional profiling by cDNA-AFLP and its modified cDNA-AFLP technique reveals gene expression of tea (Camellia sinensis) during flower bud development stage. Acta Laser Biol. Sin. 17: 733-738.

Yong WD, Chong K, Xu ZH, Tan KH, et al. (2000). Gene control of flowering time in higher plants. Chin. Sci. Bull. 45: 1633-1642.

Yu G, Ma YX, Duan JA, Song BS, et al. (2012). Identification of differentially expressed genes involved in early bolting of Angelica sinensis (Apiaceae). Genet. Mol. Res. 11: 494-502.

Yu H, Ito T, Zhao Y, Peng J, et al. (2004). Floral homeotic genes are targets of gibberellin signaling in flower development. Proc. Natl. Acad. Sci. U. S. A. 101: 7827-7832.

Yu XJ (1985). The Activity Measurement of Sucrose Synthase and Sucrose Phosphate Synthase. 1st edn. Shanghai Science and Technology Press, Shanghai. 